\title{
Rheology of Star-Branched Polyisobutylene
}

\author{
P. G. Santangelo and C. M. Roland* \\ Chemistry Division, Code 6120, Naval Research Laboratory, Washington, D.C. 20375-5342

\section{J. E. Puskas}

Department of Chemistry \& Biochemical Engineering, University of Western Ontario, London, Ontario N6A 5B9, Canada

Received October 2, 1998; Revised Manuscript Received J anuary 4, 1999

\begin{abstract}
The rheology of high molecular weight, six-arm-star polyisobutylenes (PIB) was measured and compared to the behavi or of linear PIB. The polymers had equivalent plateau moduli and conformed well in the terminal zone to the time-temperature superposition principle. Moreover, the temperature coefficients of the terminal relaxation times were identical for the star and linear polymers. Since the trans and gauche conformations in PIB have virtually the same energy, this absence of enhanced temperature sensitivity in star PIB, as well as the thermorheological simplicity, is consistent with an interpretation of the rheology of branched polymers based on an arm retraction mechanism.
\end{abstract}

\section{Introduction}

The complex rheology of entangled polymers continues to be widely studied, several review articles having appeared in the past several years. ${ }^{1-5}$ One aspect evoking particular interest is the effect of long chain branching. ${ }^{6-8}$ Well-entangled arms suppress Iongitudinal motions, ${ }^{9}$ resulting in slower relaxation and higher viscosities. Reptation of a branched polymer cannot transpire without some additional mechanism to allow diffusion along the chain contour. The general consensus is that stress relaxation and diffusion entail arm retraction, which causes an exponential increase with branch length of both the zero-shear viscosity and the diffusion constant. ${ }^{10-18}$

This arm retraction is believed 19 to be the cause of two other phenomena associated with branched polymers: more temperature-dependent rheological properties and thermorheological complexity in the terminal zone. ${ }^{20-27}$ The transient, compact structure would alter the distribution of rotational states, in turn giving rise to a thermal barrier to terminal relaxation, which is absent for linear polymers. If the gauche rotamers, which predominate in a more compact configuration, are higher in energy than the trans conformers, the model of Graessley ${ }^{19,20}$ predicts the existence of an energy barrier, $E_{A}$, whose magnitude is proportional to the molecular weight, $M_{a}$, of the branch

$$
\mathrm{E}_{\mathrm{A}}=\Lambda \frac{\mathrm{M}_{\mathrm{a}}}{\mathrm{M}_{\mathrm{e}}}
$$

where $\mathrm{M}_{\mathrm{e}}$ is the entanglement molecular weight. The proportionality constant, $\Lambda$, would be chemical structure dependent, reflecting the gauche/trans energy difference. ${ }^{19,20}$

Thus, this interpretation of the rheology of branched polymers leads to the prediction that their excess activation energy will correlate with the relative energy of the bond conformations. The latter can be assessed from the temperature coefficient of the chain dimensions, $\kappa \equiv d \ln \left\langle r^{2}\right\rangle / d T$, where $\left\langle r^{2}\right\rangle$ is the second moment of the chain end-to-end distance. $\kappa$ can be evaluated from the temperature dependence of the intrinsic viscosity
Table 1. Polyisobutylene Samples

\begin{tabular}{llrcc}
\hline & structure & $\mathrm{M}_{\mathrm{w}}{ }^{\mathrm{a}}$ & $\mathrm{M}_{\mathrm{w}} / \mathrm{M}_{\mathrm{n}}$ & $\mathrm{M}_{\mathrm{a}} / \mathrm{M}_{\mathrm{e}}{ }^{\mathrm{b}}$ \\
\hline L176 & linear & 176000 & 1.6 & \\
S217 & 6-arm star & 217000 & 1.19 & 4 \\
S490 & 6-arm star & 490000 & 1.18 & 9 \\
a SEC/MALLS. ${ }^{\circ} \mathrm{M}_{\mathrm{e}}=9400 \mathrm{~g} / \mathrm{mol}$. & &
\end{tabular}

or, when the polymer is cross-linked, the temperature dependence of the elastic stress. ${ }^{28}$

Experimental data corroborating eq 1 are problematic. Results for hydrogenated polyisoprene, polyethylene, ${ }^{20,21}$ and 1,2-polybutadiene are qualitatively consistent with the predicted correlation between an excess temperature dependence for branched chains with their conformational energies.19,20 On the other hand, the gauche conformers of 1,4-polyisoprene are lower in energy than the trans; ${ }^{28,29}$ nevertheless, the presence of long branches gives rise to larger temperature coefficients than linear polyisoprene. ${ }^{25-27}$ Branched 1,4-polybutadiene exhibits a similar anomaly-stronger temperature dependence ${ }^{20}$ even though the retracted configuration should be the lower energy state. ${ }^{29} \mathrm{~F}$ or polystyrene and hydrogenated 1,2-polybutadiene, the only available data were obtained on polymers too low in molecular weight to be a sensitive test of the arm retraction hypothesis.

Polyisobutylene presents an interesting case. Thermoelastic measurements indicate a negligible magnitude for $\kappa\left(<10^{-4} 29,30\right)$, about an order of magnitude smaller than the temperature coefficient for other polymers in which the effect of branching has been investigated. ${ }^{27}$ This means that the gauche and trans conformational energies are essentially equal $(\Lambda \approx 0)$, and thus eq 1 predicts branching will have no effect on the temperature coefficient of the rheol ogical properties. With the recent development of synthetic methods for producing star-branched PIB of high molecular weight, ${ }^{31,32}$ this prediction can be experimentally tested.

\section{Experimental Section}

The polyisobutylenes included two star-branched and a linear PIB (Table 1). The star polymers were synthesized using a multifunctional initiator, hexaepoxysqualene (HES), in conjunction with $\mathrm{TiCl}_{4}{ }^{32}$ The branched structure was analyzed 


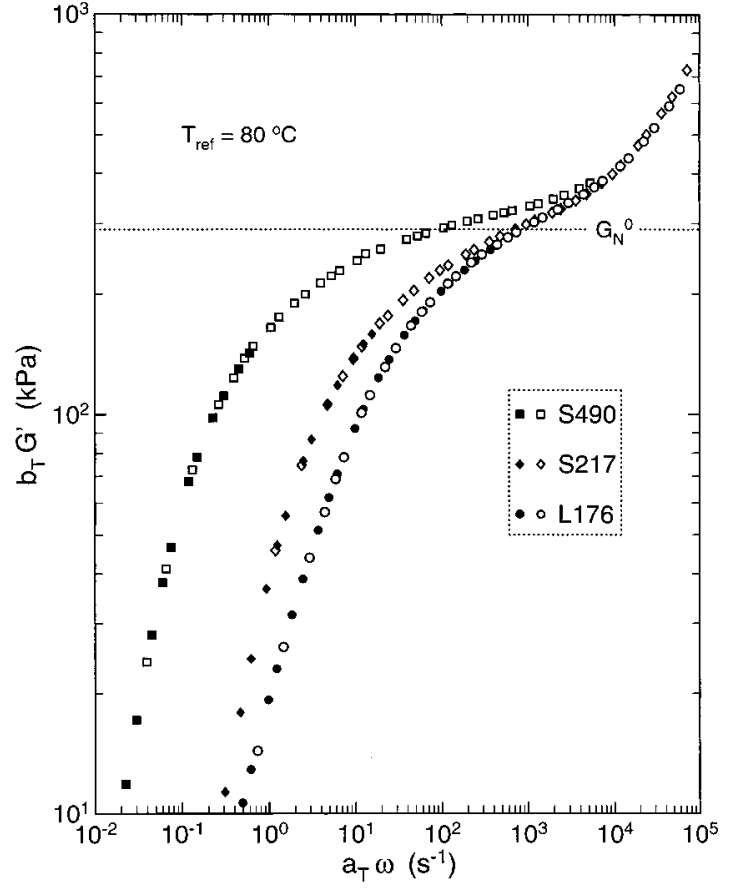

Figure 1. Storage modulus of the linear PIB $\left(\mathrm{O},-10^{\circ} \mathrm{C}\right.$; $\bullet$ $\left.90^{\circ} \mathrm{C}\right)$ and for the low $\left(\diamond,-18{ }^{\circ} \mathrm{C} ; \diamond, 90^{\circ} \mathrm{C}\right)$ and the high $(\square$ $4{ }^{\circ} \mathrm{C}$;, $150^{\circ} \mathrm{C}$ ) molecular weight PIB stars. The horizontal line denotes the value of the plateau modulus obtained from eq 6. Note that the limiting behavior $\mathrm{G}^{\prime}(\omega) \propto \omega^{2}$ is not attained at the lowest frequencies due to polydispersity.

by diphenylethylene end-capping experiments using proton NMR. A kinetic analysis of the HES-initiated polymerizations indicated that rates of monomer consumption were 5-6 times faster with HES than with the monofunctional 2-chloro-2,4,4trimethylpentane/ $\mathrm{TiCl}_{4}$ initiating system, ${ }^{33}$ used to synthesize the linear PIB. Linearity of the monomer consumption plots, together with the linearity of the molecular weight-conversion plots, demonstrated an absence of detectable termination and chain transfer. Molecular weights were determined by SEC with MALLS detection.

Dynamical mechanical measurements (Bohlin VOR) were made using a parallel plate geometry (sample radii and gaps were ca. 6 and $1.3 \mathrm{~mm}$, respectively). The dynamic shear modulus was measured isothermally over the frequency range $10^{-4} \leq \omega \leq 10^{1} \mathrm{rad} / \mathrm{s}$, at strains from 0.1 to $10 \%$. The spectra were obtained from the midpoint of the softening zone down to frequencies approaching the Newtonian regime. For the highest molecular weight sample (S490), this entailed a 150 deg range of temperatures. Zero-shear rate viscosities were measured by torsional creep (Haake Rheostress RS 150) carried out over 3 days time in order to attain steady state. Even so, a small Ninomiya correction ${ }^{34}$ was applied to the data.

\section{Results}

Although PIB exhibits thermorheological complexity in its softening zone, ${ }^{35}$ measurements restricted to the terminal and plateau regions have been found to superposition well, at least for linear PIB. ${ }^{36-38}$ Displayed in Figures 1 and 2 are the master curves of the storage, $G^{\prime}(\omega)$, and the loss, $G^{\prime \prime}(\omega)$, moduli for the PIB at a reference temperature, $\mathrm{T}_{\text {ref }}=80^{\circ} \mathrm{C}$. (F or clarity, only two temperatures are shown, representing the extremes of the measured range.) The curves were constructed by superimposing the phase angle, $\tan ^{-1} \mathrm{G}^{\prime \prime}(\omega) / \mathrm{G}^{\prime}(\omega)$, to obtain the time-temperature shift factors, aT. Vertical shift factors, $b_{\top}$, were then determined empirically from superposition of the modulus data.

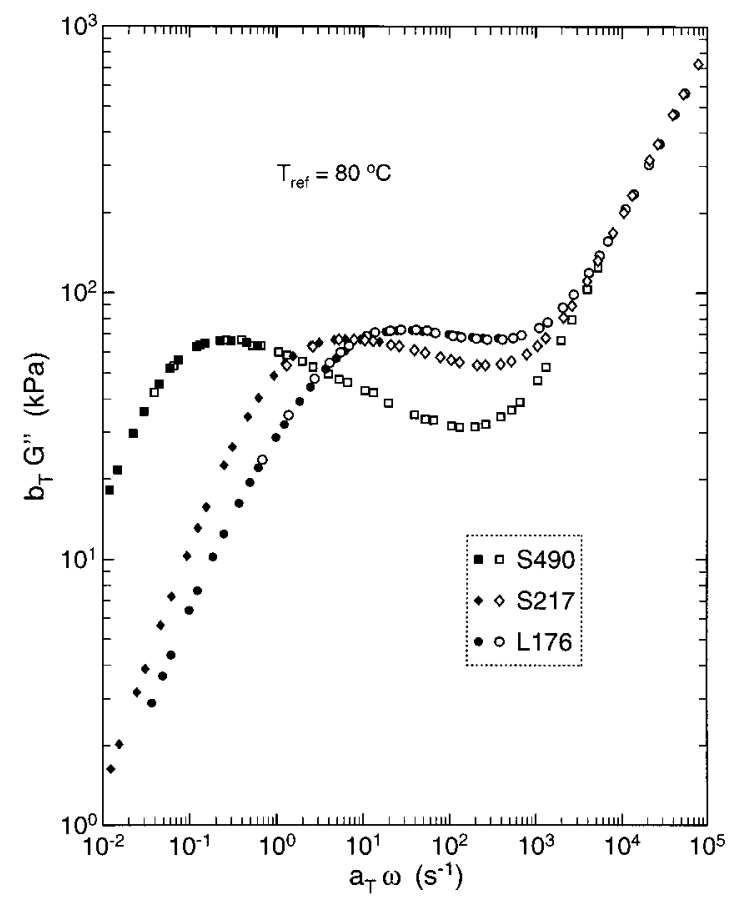

Figure 2. Loss modulus of linear and star-branched PIB (symbols are defined in Figure 1).

According to the Rouse model, the magnitude of the modulus variation with temperature depends only on the number density of chains and their entropic contribution to the force; this leads to a simple relation for the modulus shift factors ${ }^{39}$

$$
\mathrm{b}_{\mathrm{T}}=\frac{(\rho \mathrm{T})_{\text {ref }}}{\rho \mathrm{T}}
$$

where $\rho$ is the mass density. This expression is known to poorly reproduce experimentally determined values of $b_{\text {T. }}$. From a scaling analysis of the entanglement interaction in polymers, Graessley and E dwards derived an alternative prediction, valid in the terminal and plateau zones. ${ }^{40}$

$$
\mathrm{b}_{\mathrm{T}}=\frac{\left(\rho^{2}\left\langle\mathrm{r}^{2}\right\rangle T\right)_{\mathrm{ref}}}{\rho^{2}\left\langle\mathrm{r}^{2}\right\rangle \mathrm{T}}
$$

From eq 3 , the modulus shift factors for PIB were calculated using the reported temperature dependence of its mass density 36

$$
\rho^{-1}=1.077+6.8 \times 10^{-4} \mathrm{~T}(\mathrm{~K})
$$

and its characterizitic ratio ${ }^{28,41}$

$$
\mathrm{C}_{\infty}=7.112 \exp \left[-2 \times 10^{-4} \mathrm{~T}(\mathrm{~K})\right]
$$

(which has the same temperature dependence as $\left\langle r^{2}\right\rangle$ ). As seen in Figure 3, eq 3 provides a good approximation to the experimental b- and certainly is an improvement over the Rouse prediction.

Although the thermorheological simplicity apparent in Figures 1 and 2 is the norm for linear polymers, a breakdown of time-temperature superpositioning is often encountered for branched chains in the terminal zone. ${ }^{19,20,25,42}$ To better illustrate the degree of thermorheological simplicity found herein, the loss modulus measured at all temperatures for the higher molecular 


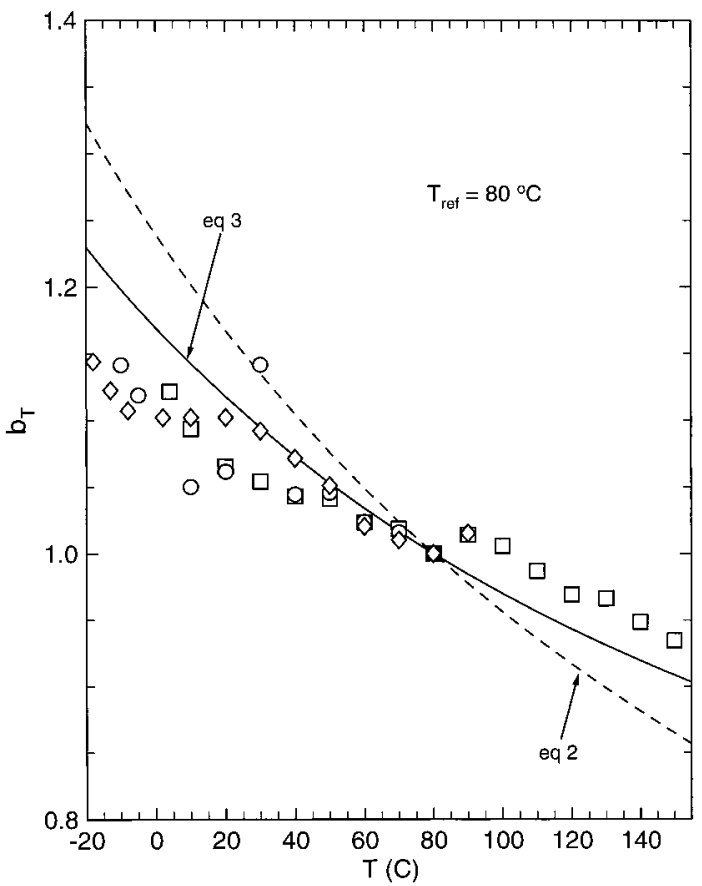

Figure 3. Modulus shift factors for PIB $(O, L 176$; $\diamond$, S217; $\square$, S490), along with the vertical shifting predicted by eq 2 $(--)$ and eq $3(-)$, respectively.

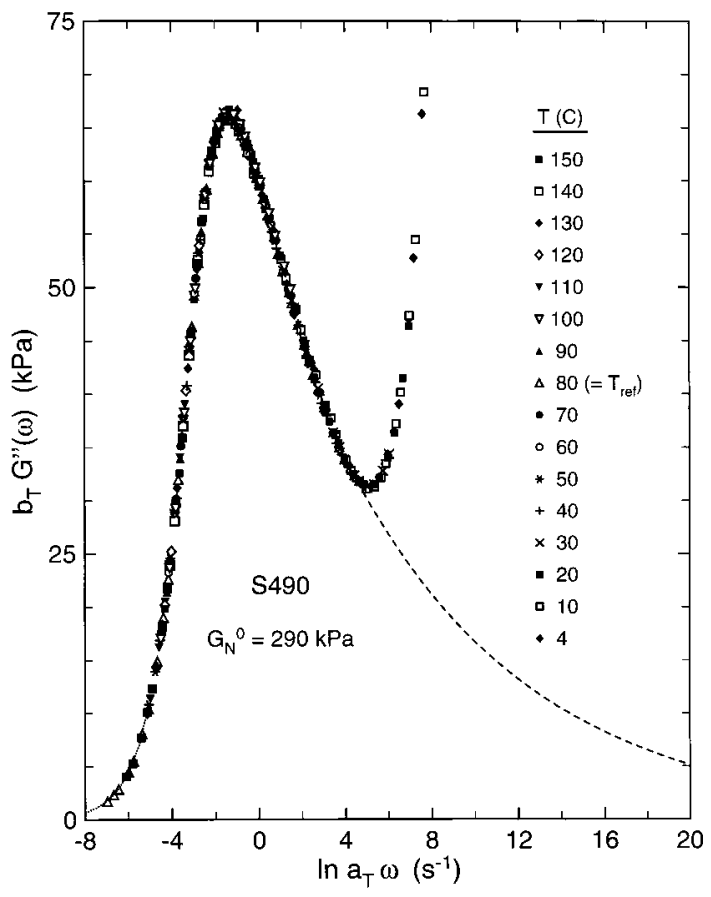

Figure 4. Semilogarithmic plot of the terminal peak in the loss modulus measured at various temperatures, with $\mathrm{T}_{\text {ref }}=$ $80{ }^{\circ} \mathrm{C}$. Integration, using the indicated extrapolation on the high-frequency side to separate the partially overlapping transition zone, yields a value for the plateau modulus.

weight star PIB is displayed in Figure 4 on a linear ordinate scale. Encompassing more than 5 decades of actually measured frequencies, the near-perfect superpositioning demonstrates the absence herein of a common and noteworthy effect of long-chain branching on the rheology.

The storage moduli in Figure 1 for the three PIB converge at higher frequencies, consistent with the expectation that the entanglement structure should be unaffected by branching. From the Kronig-Kramers

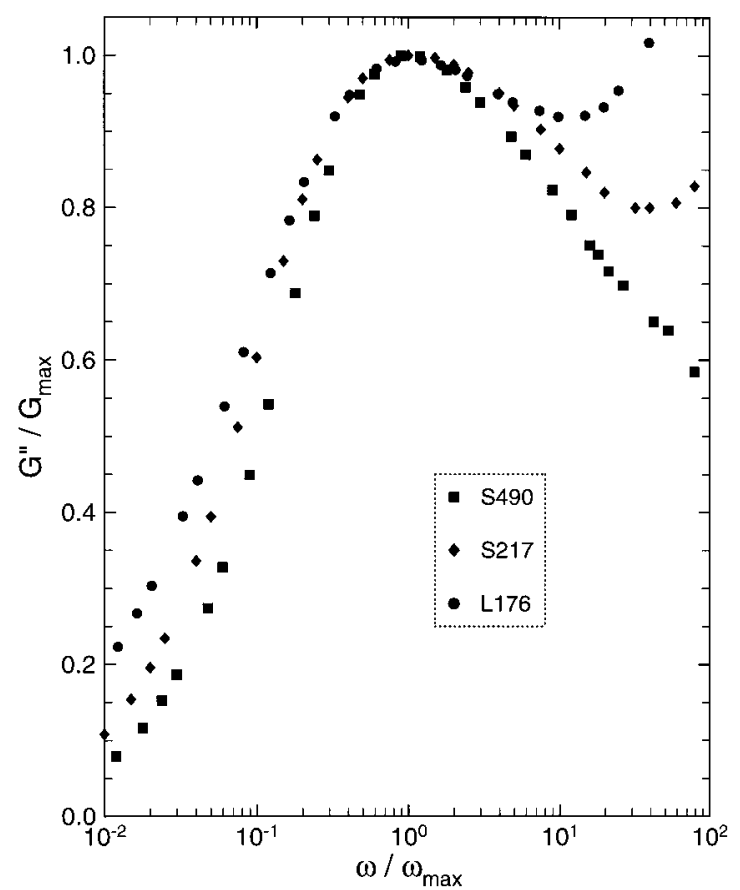

Figure 5. Terminal dispersions of the linear and star PIB, normalized to superimpose the peaks. The peak breadths primarily reflect polydispersity of the molecular weights. Encroachment of the transition zone is seen at higher frequencies.

relation 39,43

$$
\mathrm{G}_{\mathrm{N}}^{0}=\frac{2}{\pi} \int_{-\infty}^{\mathrm{a}} \mathrm{G}^{\prime \prime}(\omega) \mathrm{d} \ln \omega
$$

the plateau modulus, $\mathrm{G}_{N}^{0}$, was obtained by integration of the peak in the loss modulus (Figure 4). The result for the three polymers, $\mathrm{G}_{\mathrm{N}}^{0}=290 \mathrm{kPa}$ (indicated by the dotted line in Figure 1), is intermediate between two published values for linear PIB, $250^{44}$ and $320^{36} \mathrm{kPa}$. From the entanglement molecular weight of PIB calculated from the plateau modulus, $\mathrm{M}_{\mathrm{e}}\left(=\rho \mathrm{RT} / \mathrm{G}_{\mathrm{N}}^{0}\right)=9400$ $\mathrm{g} / \mathrm{mol}$, we estimate the degree of entanglement of the PIB arms listed in Table 1.

Determination of the plateau modulus from eq 6 is unaffected by the molecular weight distribution, even though the latter alters the shape of the terminal dispersion. However, the different polydispersities of the PIB herein preclude interpretation of their relaxation functions in terms of the dynamics. Generally, the terminal zone for a star-branched polymer is broader than for the linear homologue. ${ }^{45}$ The opposite result seen in Figure 5 presumably is due to the greater polydispersity of the L176 (Table 1). In addition, on the highfrequency side of the terminal peak, there is overlapping with the glass transition zone. This interference diminishes for the higher molecular weight stars, although complete separation of the terminal zone from the higher frequency motions requires molecular weights ca. a 100-fold higher than $\mathrm{M}_{\mathrm{e}}{ }^{45}$ which is more than the $\mathrm{M}_{\mathrm{w}}$ herein (viz. Table 1 ).

Molecular weight polydispersity also influences the terminal viscosities, as has been shown for PIB specifically. ${ }^{46}$ The values measured in shear for the three polymers are listed in Table 2 and displayed as a function of weight-average molecular weight in Figure 6 . Also included in the figure are the data for linear PIB as reported by Fetters et al. ${ }^{36}$ 
Table 2. Rheological Properties

\begin{tabular}{ccccc}
\hline & $\eta_{0^{\mathrm{a}}}(\mathrm{MPa} \cdot \mathrm{s})$ & $\tau_{0}^{\mathrm{b}}(\mathrm{s})$ & $\mathrm{B}^{\mathrm{b}}$ & $\mathrm{T}_{\infty}(\mathrm{K})^{\mathrm{b}}$ \\
\hline L176 & 8.9 & $1.96 \times 10^{-8}$ & 3667 & 98.8 \\
S217 & 6.8 & $5.26 \times 10^{-8}$ & 3858 & 92.7 \\
S490 & 132. & $2.02 \times 10^{-7}$ & 3753 & 94.7
\end{tabular}

a At $25^{\circ} \mathrm{C} .{ }^{\mathrm{b}}$ Equation 9.

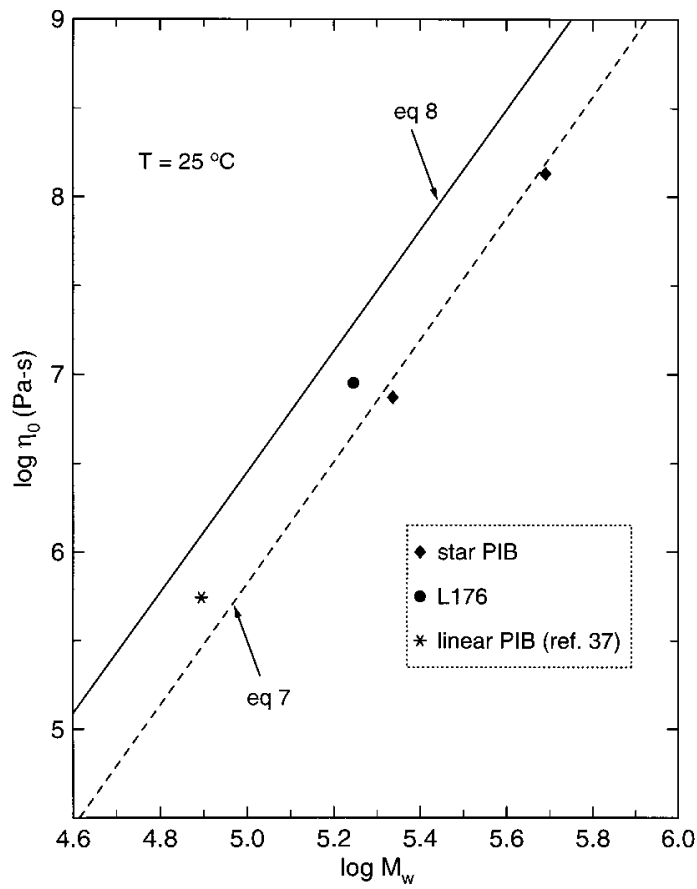

Figure 6. Zero shear viscosity for linear (circle) and starbranched (diamond) PIB, along with literature results for linear PIB (dashed line, ref 36; solid line, ref 47; asterisk, ref 37). For the data represented by the solid line, the abscissa is actually $\mathrm{M}_{\mathrm{v}}$, rather than the weight-average molecular weight.

$$
\eta_{0}=4.69 \times 10^{-12} \mathrm{M}_{\mathrm{w}}^{3.43}
$$

and by Fox and Flory ${ }^{47}$

$$
\eta_{0}=2.82 \times 10^{-11} \mathrm{M}_{\mathrm{v}}^{3.40}
$$

at $25{ }^{\circ} \mathrm{C}$ in units of Pa.s. In eq 8, Mv refers to the molecular weight deduced from the intrinsic viscosity of fractionated (i.e., monodisperse) samples. The difference between these two equations is due in part to differences in the respective molecular weight determinations. ${ }^{36}$ Our value for L176, although intermediate between the two curves in Figure 6, is consistent with the viscosity obtained by Plazek et al. for a lower molecular weight PIB. ${ }^{37}$

The terminal viscosity can be used to assess the temperature dependence of PIB; however, the results are sensitive to errors in torque, sample geometry, etc., which may themselves change with temperature. This potential problem is avoided by relying on theterminal relaxation time, which has the same temperature dependence as $\eta_{0}$. A terminal relaxation time, $\tau_{\max }$, can be defined as the reciprocal of the frequency of the loss modulus maximum, $\left(\mathrm{dG}^{\prime \prime}\left(1 / \tau_{\max }\right) / \mathrm{d} \omega=0\right)$. For a monodisperse polymer, $\tau_{\max } \approx \eta_{0} / \mathrm{G}_{\mathrm{N}}^{0} .{ }^{45} \mathrm{In}$ Figure 7 these $\tau_{\max }$ are plotted, along with fits to the Vogel-Fulcher equation $^{39}$

$$
\tau_{\max }=\tau_{0} \exp \left(\frac{\mathrm{B}}{\mathrm{T}-\mathrm{T}_{0}}\right)
$$

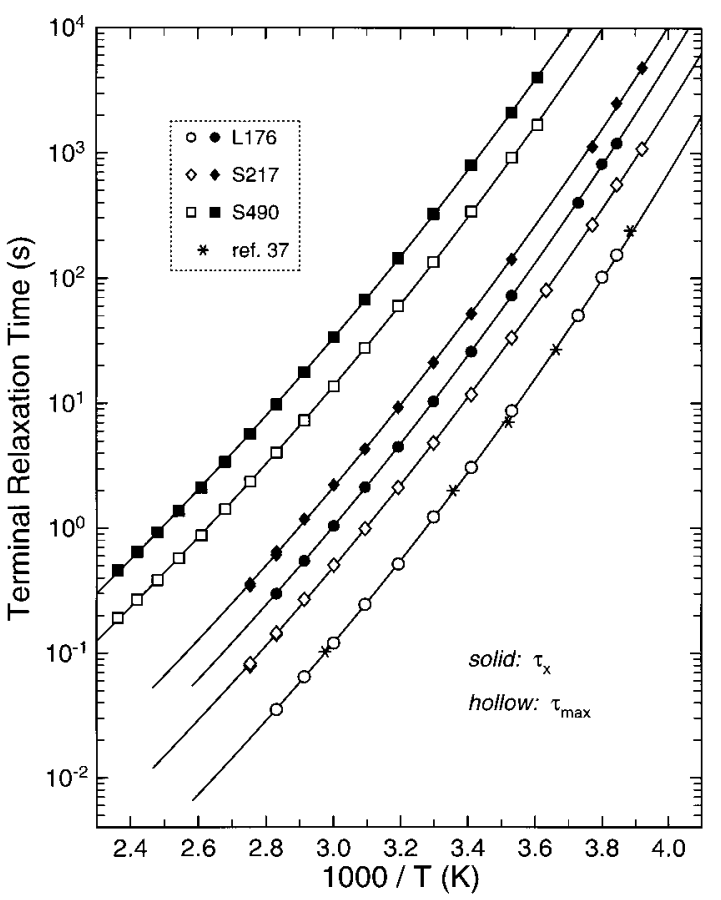

Figure 7. Reciprocal of the frequency of the loss modulus maximum (solid symbols) and of the crossover frequency (hollow symbols). The lines represent fits to the Vogel-Fulcher equation. The asterisks are shift factors from Plazek et al.,37 vertically scaled to superpose on the data for L 176.

which is equivalent to the WLF equation. The VF parameters are listed in Table 2. Also included in Figure 7 are the time-temperature shift factors reported by Plazek et al. ${ }^{37}$ for a linear PIB.

An alternative characteristic time for the terminal relaxation is the crossover time, $\tau_{\times}$, which is the inverse of the frequency at which $\mathrm{G}^{\prime}(\omega)=\mathrm{G}^{\prime \prime}(\omega)$. Values for $\tau_{\times}$ are included in Figure 7. It can be seen that $\tau_{\times}$and $\tau_{\max }$ have the same temperature dependence, reflecting the thermorheol ogical simplicity of the PIB. Moresignificant is the fact that all curves in Figure 7 are parallel. Along with the near equivalence of their respective VF parameters (Table 2 ), this indicates that temperature changes have the same effect on the rheology of linear and star-branched PIB.

This observation can be made more explicit by replotting $\tau_{\max }$ for the stars after normalizing by the relaxation time of $\mathrm{L} 176$ measured at the same temperature..$^{20}$ The resulting curves (Figure 8) have essentially zero slope, demonstrating that branching does not change the temperature dependence of PIB.

\section{Discussion}

The fact that the temperature dependence of the starbranched polymers is the same as that of linear PIB is only significant if the branches are well-entangled. We expect this to be the case at least for S490, which has roughly nine entanglements per arm (Table 1 ) and a well-developed plateau in the storage modulus (Figure 1 ). The viscosity of polymers having sufficiently long branches will have a stronger dependence on molecular weight than the power law found for linear chains (eqs 2 and 3). An exponential relationship has been proposed $^{15-17}$

$$
\eta_{0} \propto\left(\frac{\mathrm{M}_{\mathrm{a}}}{\mathrm{M}_{\mathrm{e}}}\right)^{\mathrm{b}} \exp \left(\frac{v \mathrm{M}_{\mathrm{a}}}{\mathrm{M}_{\mathrm{e}}}\right)
$$




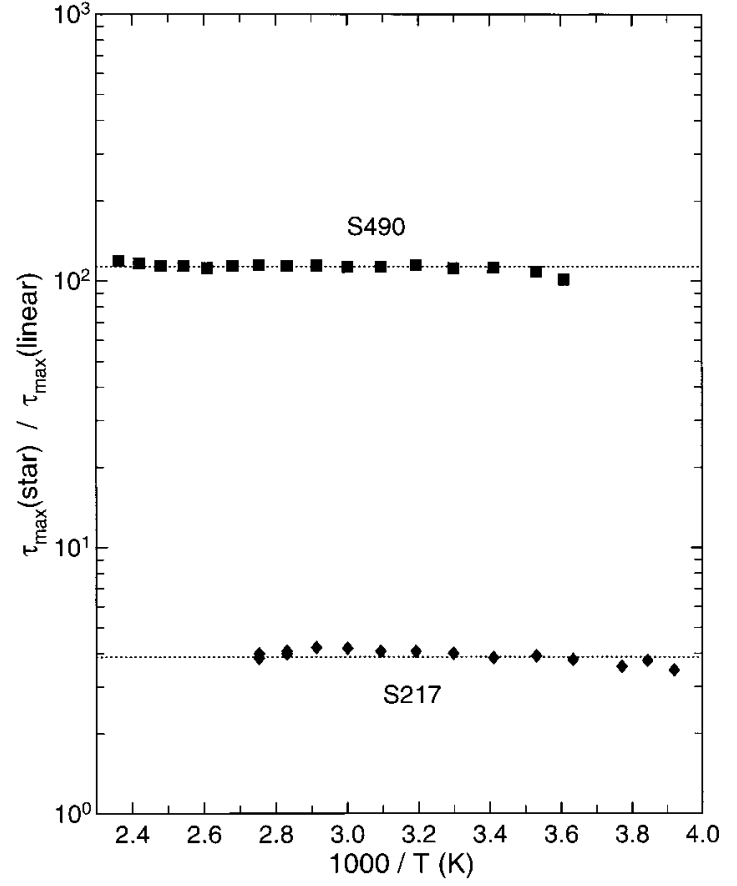

Figure 8. Arrhenius plots of the ratio of the terminal relaxation times for branched and linear PIB. The negligible slope indicates no enhanced temperature dependence due to the branching.

(where $v$ and $\mathrm{b}$ are close to unity), which serves to emphasize the overriding importance of branch length. Since only two branched samples were available, we cannot assess herein the molecular weight dependence of the PIB stars. Nevertheless, it is tempting to point out that the slope of the star data in Figure 6 is larger than the value of 3.4 for linear PIB. ${ }^{36,47}$

According to the Graessley interpretation, 19,20 when the branches are highly entangled, the temperature coefficient of rheological properties will be enhanced (eq 1 ) to an extent dependent on $\Lambda$, that is, dependent on the difference between the trans and gauche conformational energies. Thus, thermoelasticity results 29,30 indicating that $\Lambda \approx 0$ for PIB lead to the prediction that the excess activation energy for branched PIB will be zero. This prediction is in accord with Figure 8.

The coupling model of relaxation ${ }^{48,49}$ offers an alternative approach to the effect long branches have on the rheology. According to this model, ${ }^{50,51}$ entangled arms will enhance intermolecular cooperativity and thus al ways result in more temperature-sensitive rheological properties. This prediction, which is independent of the trans/gauche conformational energies, ${ }^{52}$ appears to be at odds with our PIB data. On the other hand, the Graessley interpretation, while successfully describing the present results, fares less well in the case of branched 1,4-polybutadiene ${ }^{20}$ and 1,4-polyisoprene. ${ }^{25-27}$ Evidently, further experiments, with other branched polymers and higher molecular weight samples, are needed to clarify this situation.

Acknowledgment. The work at NRL was supported by the Office of Naval Research. Wethank W. E. Pattern for assisting with the polymer synthesis.

\section{References and Notes}

(1) Lodge, T. P.; Rotstein, N. A.; Prager, S. Adv. Chem. Phys. 1990, 79, 1.

(2) Adachi, K.; Kotaka, T. Polym. Yearbook 1990, 6, 43.
(3) Doi, M. In Structureand Properties of Polymers; Thomas, E. L., Ed.: Wiley-VCH: Weinheim, 1993; Chapter 9.

(4) Graessley, W. W. In Physical Properties of Polymers, 2nd ed.; American Chemical Society: Washington, DC, 1993; Chapter 3.

(5) Ngai, K. L.; Plazek, D. J . Rubber Chem. Technol. 1995, 68, 376

(6) Grest, G. S.; Fetters, L. J .; Huang, J . S.; Richter, D. Adv. Chem. Phys. 1996, 94, 67

(7) Bauer, B. J .; Fetters, L. J . Rubber Chem. Technol. 1978, 51, 406.

(8) Graessley, W. W. Acc. Chem. Res. 1977, 10, 332.

(9) Long, V. C.; Berry, G. C.; Hobbs, L. M. Polymer 1964, 5, 517.

(10) Kraus, G.; Gruver, J. T. J . Polym. Sci. A 1965, 3, 105.

(11) Berry, G. C.; Fox, T. G. Adv. Polym. Sci. 1968, 5, 261.

(12) de Gennes, P. J . Phys. (Paris) 1975, 36, 1199.

(13) Klein, J .; Fletcher, D.; Fetters, L. J.J . Chem. Soc., Faraday Symp. 1983, 18, 159

(14) Klein, J. Macromolecules 1986, 19, 105.

(15) Doi, M.; Kuzuu, N. Y. J . Polym. Sci. Lett. Ed. 1980, 18, 775

(16) Pearson, D. S.; Helfand, E. Macromolecules 1984, 17, 888.

(17) Fetters, L. J .; Kiss, A. D.; Pearson, D. S.; Quack, G. F.; Vitus, F.J. Macromolecules 1993, 26, 647.

(18) Roovers, J. Polymer 1985, 26, 1091.

(19) Graessley, W. W. Macromolecules 1982, 15, 1164.

(20) Carella, J. M.; Gotro, J . T.; Graessley, W. W. Macromolecules 1986, 19, 659 .

(21) Raju, V. R.; Rachapudy, H.; Graessley, W. W. J . Polym. Sci. Polym. Phys. Ed. 1989, 17, 1223.

(22) Porter, R. S.; Knox, J . P.; J ohnson, J . F. Trans. Soc. Rheol 1968, 12, 409.

(23) Mendel son, R. A.; Bowles, W. A.; Finger, F. L. J . Polym. Sci., Polym. Phys. Ed. 1970, 8, 105.

(24) Gell, C. B.; Graessley, W. W.; Efstratiadis, V.; Pitsikalis, M.; Hadjichristidis, N. J . Polym. Sci., Polym. Phys. Ed. 1997, 35, 1943.

(25) Bero, C. A.; Roland, C. M. Macromolecules 1996, 29, 1562.

(26) Roland, C. M.; Bero, C. A. Macromolecules 1996, 29, 7521.

(27) Santangelo, P. G.; Roland, C. M. J . Non-Cryst. Solids 1998 235-237, 709.

(28) Flory, P. J . Statistical Mechanics of Chain Molecules; Carl Hanser Verlag: New York, 1989.

(29) Erman, B.; Mark, J . E. Structures and Properties of Rubberlike Networks; Oxford University Press: New York, 1997

(30) Suter, U. W.; Saiz, E.; Flory, P. J . Macromol ecules 1983, 16, 1006.

(31) Puskas, J . E.; Kaszas, G.; Kennedy, J . P.; Kelen, T.; Tudos, F. J Macromol. Sci., Chem. 1982-83, A18, 1229.

(32) Puskas, J. E.; Pattern, W.; Westmore, P. M.; Krukonis, V Rubber Chem. Technol., in press.

(33) Gyor, M.; Fodor, Z.; Wang, H.-C.; Faust, R. J . Macromol. Sci., Pure Appl. Chem. 1994, A31(12), 2055.

(34) Ninomiya, K. J . Phys. Chem. 1963, 67, 1152.

(35) Plazek, D. J .; Chay, I.-C.; Ngai, K. L.; Roland, C. M. Macromolecules 1995, 28, 6432.

(36) Fetters, L. J .; Graessley, W. W.; Kiss, A. D. Macromolecules 1991, 24, 3136

(37) Plazek, D. J .; Zheng, X. D.; Ngai, K. L. Macromol ecules 1992 25, 4920.

(38) Okamoto, H.; I noue, T.; Osaki, K. J . Polym. Sci., Polym. Phys. Ed. 1995, 33, 1409.

(39) Ferry, J . D. Viscoelastic Properties of Polymers; Wiley: New York, 1980.

(40) Graessley, W. W.; Edwards, S. F. Polymer 1981, 22, 1329.

(41) Fetters, L. J .; Hadjichristidis, N.; Lindner, J . S.; Mays, J . W.; Wilson, W. W. Macromolecules 1991, 24, 3127.

(42) The situation concerning 1,4-polyisoprene is somewhat confused. A detailed analysis in ref 25 clearly demonstrated breakdown of time-temperature superpositioning in the terminal zone for well-entangled three-arm stars. Milner and McLeish, on the other hand, recently published master curves for star-branched polyisoprene [Milner, S. T.; McL eish, T. C. B. Macromolecules 1998, 31, 7479], implying thermorheological simplicity. However, the scatter in their doublelogarithmic plots opens to question the quality of the superpositioning. Note, for example, that ostensibly satisfactory master curves can be constructed for the softening dispersion in polyisoprene, even though the behavior in the transition zone is thermorheologically complex [Santangelo, P. G.; Roland, C. M. Macromolecules 1998, 31, 3715].

(43) Sanders, J. F.; Ferry, J . D. Macromolecules 1969, 2, 440.

(44) Ferry, J. D.; Grandine, L. D.; Fitzgerald, E. R. J . Appl. Phys 1953, 24, 911 
(45) Raju, V. R.; Menezes, E. V.; Marin, G.; Graessley, W. W.; Fetters, L. J. Macromol ecules 1981, 14, 1668

(46) Wasserman, S. H.; Graessley, W. W. J . Rheol. 1992, 36, 543.

(47) Fox, T. G.; Flory, P.J . J . Phys. Colloid Chem. 1951, 55, 2513.

(48) Ngai, K. L.; Plazek, D. J .; Rendell, R. W. Rheol. Acta 1997, $36,307$.

(49) Santangelo, P. G.; Ngai, K. L.; Roland, C. M. Polymer 1998, 39,681 .
(50) Ngai, K. L.; Rendell, R. W. Polym. Prepr. 1982, 23 (2), 46.

(51) Ngai, K. L.; Roland, C. M. J . Polym. Sci., Polym. Phys. Ed. 1997, 35, 2503.

(52) Ngai, K. L.; Plazek, D. J . J . Polym. Sci., Polym. Phys. Ed. 1985, 23, 2159.

MA9815556 